\title{
ANALISIS KANDUNGAN PLASTIK PADA GORENGAN DI KAWASAN PERGURUAN TINGGI KOTA PADANG
}

\author{
Media Roza, Milya Sari, Nurhasnah \\ Universitas Islam Negeri Imam Bonjol Padang \\ Jl. Prof. Mahmud Yunus Lubuk Lintah, Anduring, Kuranji, Kota Padang \\ Email: mediarozaipa@gmail.com,milyasari.iain@gmail.com,hasanahbio@gmail.com
}

\begin{abstract}
Nowadays, there are many foods that contain harmful substances in the community. Among them are fried foods that contain plastic. Similar cases were also found in the campus area in city of Padang. Based on preliminary observations it was found that some fried foods sold in one campus area in the city of Padang were indicated to contain plastic. This study therefore aims to determine whether fried foods sold in the city of Padang contained plastic, what the physical characteristics of fried foods that contain plastic were, and what plastic content contained in the cooking oil. This type of research was descriptive qualitative. Sampling in this study was conducted by purposive sampling in 16 locations around the campus area in the city of Padang. The data of the research data were obtained from physical and chemical sample identifications. Physical identification included data on shape, color, fragility, and fuel test. Physically indicated samples containing plastic then analyzed chemically with GC-MS. The results of the study showed that the physical characteristics of fried foods that contain plastic were black clots when observed with a microscope, there are white patches on the surface of the fried, brittle for hours, and if it was burned, it burnt and produced melt. The results of the chemical analysis showed that from 16 sampling points 11 samples $(68.75 \%)$ positive contained plastic. The type of plastic compound found was from PVC (Polyvinyl chloride).
\end{abstract}

Key words: Plastic-containing fries, physics test, GC-MS chemical test

\section{PENDAHULUAN}

Makanan merupakan satu diantara kebutuhan dasar manusia, karena melalui makanan manusia dapat memperoleh sumber energi untuk bertumbuh, dan berkembang. Idealnya makanan yang dikonsumsi oleh manusia adalah makanan yang menyehatkan, yaitu makanan yang mengandung gizi seimbang dan tidak mengandung zat-zat yang berbahaya bagi tubuh termasuk bahan tambahan yang terlarang, mikroba penyebab penyakit, ataupun toksin (Laksmi, 2001).

Perintah untuk memakan makanan yang halal dan baik (halalan thoyyiban) terdapat dalam Al Qur'an, Surat Al Maidah : 88 yang artinya:"dan makanlah makanan yang halal lagi baik (thayyib) dari apa yang telah dirizkikan kepadamu dan bertaqwalah kepada Allah dan kamu beriman kepadaNya". Allah memerintahkan umat Islam untuk memakan makansan yang bukan cuma halal, tapi juga baik (halalan thoyyiban) agar tidak berbahaya bagi tubuh. Bahkan perintah ini disejajarkan dengan bertaqwa kepada Allah, sebagai sebuah perintah yang sangat tegas dan jelas. Perintah ini juga ditegaskan dalam ayat yang lain, seperti yang terdapat pada Surat Al Baqarah : 168 yang artinya:"Wahai sekalian manusia, makanlah yang halal lagi baik dari apa yang terdapat di bumi, dan janganlah kamu mengikuti langkahlangkah syetan; karena sesungguhnya syetan itu adalah musuh yang nyata bagimu”. Halal itu bukan sekedar halal makanannya, tapi juga dari sumber bagaimana mendapatkannya pun 
harus halal. Kalau sumbernya haram seperti korupsi, mencuri, merampok, menggusur tanah rakyat dengan harga yang rendah, maka makanan yang dimakan pun meski sebetulnya halal, tetap haram.

Selain halal, makanan juga harus baik. Meski halal tapi jika tidak baik, sebaiknya tidak dimakan. Kriteria makanan yang baik adalah: 1) Bergizi tinggi; 2) Makanan lengkap dan berimbang; 3) Semua makanan tersebut mengandung karbohidrat, protein, vitamin, dan mineral yang dibutuhkan oleh tubuh. Ada baiknya ditambah dengan herbal seperti madu, pasak bumi, habbatus saudah, minyak zaitun, dan sebagainya agar tubuh kita sehat; 4) Tidak mengandung zat-zat yang membahayakan bagi kesehatan, misalnya kolesterol tinggi atau bisa memicu asam urat kita; 5) Alami yatu tidak mengandung berbagai zat kimia seperti pupuk kimia, pestisida kimia, pengawet kimia (misalnya formalin), pewarna kimia, perasa kimia (misalnya biang gula/aspartame, MSG, plastik, dsb); dan 6) Masih segar dan tidak membusuk atau basi sehingga warna, bau, dan rasanya berubah (Media Islam, 2012).

Dewasa ini banyak beredar makanan yang mengandung zat berbahaya di masyarakat diantaranya adalah gorengan. Gorengan merupakan jenis makanan yang digemari oleh masyarakat, termasuk mahasiswa. Hal ini terlihat dari banyaknya dijual gorengan baik di dalam maupun di luar kampus, yang konsumennya adalah mahasiswa, pegawai, pelajar, dan masyarakat sekitar.

Gorengan digemari karena harganya murah, enak, dan gurih. Rasa gurih gorengan merupakan daya tarik bagi pembeli, sehingga penjual gorengan berusaha untuk menyajikan gorengan yang gurih. Akan tetapi tidak semua penjual gorengan melakukan cara yang baik dalam menghasilkan gorengan yang gurih. Salah satu cara yang dilakukan oleh penjual gorengan adalah dengan menambahkan plastik pada saat menggoreng dengan tujuan agar gorengannya gurih dan tahan lama (lihat Youtube: Acara berita Investigasi Trans TV, 2011). Isu mengenai adanya gorengan berplastik ini sudah berkembang sejak tahun 2010, dan temuan lapangan membuktikan jajanan gorengan berplastik ternyata bukan sekedar isu.

Beberapa kasus sudah ditemukan di Indonesia, diantaranya adalah di sekitar kampus Universitas Brawijaya penjual gorengan menambahkan plastik pada minyak goreng (Fahimah, 2012). Hasil investigasi tim KPAI bersama BPOM menemukan pedagang gorengan yang berbuat curang dengan mencampur plastik ke dalam minyak penggorengan di kawasan Jakarta Selatan (Hartanto, 2012).

Plastik merupakan senyawa polimer atau makromolekul yang disusun oleh monomernya. Plastik banyak digunakan dalam kehidupan sehari-hari, dan tersusun atas berbagai macam zat kimia. Beberapa kandungan kimia plastik tersebut berbahaya bagi kesehatan manusia seperti dioksin, fural, bhispenol-A, stirena, dan lain-lain. Jenis plastik yang beredar juga bermacam-macam, diantaranya adalah Poly Vinyl Chlorida, Vinylidene Chlorida Resin, dan Polysterene. Penelitian di Jepang mengidentifikasi bahwa jenis plastik tersebut tergolong senyawa kimia sebagai penyebab utama kanker (karsinogen) dan perpengaruh terhadap sistem saraf pusat (D'Buletin. 2008). Sejalan dengan hasil penelitian tersebut, hasil penelitian lain menyebutkan bahwa beberapa kandungan kimia yang terdapat di dalam plastik dapat merusak rahim dan menghasilkan janin yang cacat jika di konsumsi oleh ibu hamil (Nugroho, 2004).

Berdasarkan berita yang dimuat di media lokal terbitan Padang Sumatera Barat (Padang Ekspres. 2015), melaporkan bahwa dari hasil pengujian sampel pangan tahun 2011 September 2014 ditemukan banyak sekali zatzat berbahaya dalam makanan yang beredar di Sumatera Barat, termasuk pada makanan gorengan. Kasus serupa berkemungkinan dapat juga ditemukan di kawasan sekolah, madrasah, atau kampus di Kota Padang. Sekolah, madrasah, dan kampus merupakan kawasan yang banyak ditemui penjual gorengan. Berdasarkan observasi awal ditemukan bahwa beberapa gorengan yang dijual di salah satu kawasan kampus di kota Padang terindikasi mengandung plastik. Dimana gorengan tersebut 
gurih dan krispi dalam waktu berjam-jam, terlihat bercak-bercak putih pada bagian permukaan, dan saat dibakar menghasilkan lelehan hitam mengkilap. Semua hasil observasi tersebut merupakan ciri-ciri bahwa gorengan tersebut mengandung plastik (Juarnida dan Adlim. 2012).

Hasil-hasil temuan tersebut tidak banyak berpengaruh terhadap kebiasaan mahasiswa dalam mengkomsusi gorengan. Berdasarkan hasil wawancara yang dilakukan secara acak pada bulan April-Mei 2015 terhadap mahasiswa yang sedang mengkonsumsi gorengan dan wawancara yang dilakukan dalam perkuliahan, pengetahuan mahasiswa masih sedikit tentang hal ini. Hanya sebagian kecil mahasiswa yang mengetahui adanya plastik dalam gorengan dan apa ciri-ciri gorengan yang terindikasi mengandung plastik. Hal yang sama juga terjadi sewaktu tim peneliti mewawancarai secara acak dosen di kampus tersebut. Hanya sebagaian kecil yang mengetahui dan peduli terhadap kasus gorengan yang mengandung plastik ini. Sedangkan hampir setiap hari gorengan dikonsumsi, baik di dalam kampus maupun di sekitar tempat tinggalnya.

Berdasarkan uraian di atas maka dilakukan penelitian tentang "Analisis Kandungan Plastik pada Gorengan di Kota Padang”. Penelitian ini difokuskan pada: a) identifikasi kandungan plastik pada gorengan secara fisika dan, b) analisis secara kimia terhadap gorengan yang terindikasi mengandung plastik. Dengan penelitian ini diharapkan dapat diketahui apakah terdapat kandungan plastik pada gorengan yang dijual di Kota Padang, apa saja jenis plastik yang ditambahkan, dan bagaimana pengaruh dampaknya terhadap kesehatan. Hasil ini diharapkan dapat meningkatkan pengetahuan dan kesadaran masyarakat khususnya mahasiswa tentang bahaya dari gorengan yang mengandung plastik.

Berdasarkan uraian masalah di atas, maka penelitian dilakukan di beberapa kampus di kota Padang, tujuan penelitian adalah mengetahui ada tidaknya gorengan yang dijual di kota Padang mengandung plastik, seperti apa ciri-ciri fisik gorengan yang mengandung plastik, dan apa saja jenis plastik yang terdapat dalam minyak goreng yang digunakan.

Penelitian ini dinilai urgen dilakukan karena gorengan banyak dijual di kawasan kampus di kota Padang dengan konsumen yang terdiri atas mahasiswa, pegawai, pelajar, dan masyarakat. Hasil observasi awal yang telah dilakukan pada bulan Februari - Maret tahun 2015, diperoleh data bahwa beberapa gorengan yang dijual di salah satu kampus di kota Padang teridentifikasi secara fisika mengandung plastik. Hal ini perlu dibuktikan secara kimia dengan menggunakan instrument Gas Chromatography-Mass Spectrometry (GC-MS). Dari data GC-MS akan diketahui apakah benar terdapat kandungan plastik beserta jenis plastik yang ditambahkan ke dalam minyak goreng yang digunakan. Melalui studi kepustakaan dapat diketahui bahaya jenis plastik tersebut terhadap kesehatan.

Penelitian ini diharapkan dapat memberikan informasi apakah gorengan yang dijual di sekitar kampus di kota Padang mengandung plastik, bagaimana ciri-ciri gorengan yang mengandung plastik, dan apa jenis plastik yang dicampurkan ke dalam minyak gorengan. Hasil penelitian ini dapat memberikan informasi tentang gorengan yang aman dan berbahaya bagi kesehatan, sehingga diharapkan dapat meningkatkan pengetahuan dan kesadaran konsumen terutama mahasiswa tentang bahaya dari gorengan yang mengandung plastik. Hasil penelitin ini juga bisa menjadi masukan bagi pihak kampus dalam pengelolaan pedagang makanan yang aman (food safety) terutama pedagang gorengan.

\section{METODE PENELITIAN}

Jenis penelitian ini adalah deskriptif kualitatif. Penelitian dilakukan terhadap gorengan dan minyak goreng yang digunakan oleh penjual gorengan di kota Padang.

Populasi penelitian ini adalah semua gorengan yang dijual di Kota Padang. Teknik sampling yang digunakan adalah purposive sampling (Arikunto. 2006). Sampel gorengan 
yang diambil berasal dari penjual gorengan yang ada di beberapa kampus di kota Padang. Berdasarkan hasil kajian literatur ada \pm 60 perguruan tinggi di kota Padang. Dari 60 perguruan tinggi yang dijadikan sebagai titik/lokasi penjualan gorengan tersebut, dipilih
25\% lokasi yang paling banyak konsumennya. Berdasarkan banyaknya konsumen tersebut dipilih 16 lokasi sebagai sampel penelitian.

Adapun titik lokasi pengambilan sampel dapat dilihat pada Tabel 1 di bawah ini:

Tabel 1. Lokasi Pengambilan Sampel

\begin{tabular}{lll}
\hline No & \multicolumn{1}{c}{ Lokasi (sekitar kampus) } & \multicolumn{1}{c}{ Kecamatan } \\
\hline 1 & IAIN Imam Bonjol Padang & Kuranji \\
2 & Universitas Bung Hatta dan Baiturrahmah & Kuranji \\
3 & UPI & Lubuk Begalung \\
4 & Universitas Dharma Andalas & Padang Timur \\
5 & UNP Kampus Ulu Gadut & Lubuk Kilangan \\
6 & STIKES dan Mercubhakti Jaya & Nanggalo \\
7 & STIE/KBP -STIKES & Padang Barat \\
8 & Unand (Fak. Kedokteran) & Padang Timur \\
9 & UNP & Padang Utara \\
10 & STKIP Gunung Pangilun & Padang Utara \\
11 & UNAND (Kampus Limau Manis) & Pauh \\
12 & ATIP & Koto Tangah \\
13 & Stikes Perintis & Koto Tangah \\
14 & STMIK Jaya Nusa & Padang Barat \\
15 & IAIN & Kuranji \\
16 & IAIN & Kuranji \\
\hline
\end{tabular}

Pengambilan sampel pada suatu lokasi dilakukan pada pagi dan sore hari. Identifikasi sampel secara fisika dilakukan di Laboratorium Kopertis Wilayah X Padang. Analisis GC-MS dilakukan di Balai Laboratorium Kesehatan Padang. Waktu penelitian ini dilaksanakan pada bulan Agustus-Oktober tahun 2015.

Data penelitian ini merupakan data primer. Data primer ini diperoleh dari identifikasi sampel secara fisika dan kimia. Identifikasi secara fisika meliputi data bentuk, warna, kerapuhan, dan uji bakar. Secara kimia data berupa kromatogram dan spektra massa yang diperoleh dari hasil GC-MS.

Instrumen yang digunakan untuk analisis secara fisika ini, yaitu lumpang dan mortor, cawan porselen, tripod, kasa asbes, mikroskop cahaya, wadah sampel dan lampu spritus. Instrumen yang digunakan untuk analisis secara kimia adalah GC-MS.
Prosedur yang dilakukan untuk penelitian ini meliputi 3 tahap.

a. Tahap Persiapan: menetapkan tempat penelitian, jadwal penelitian, dan menentukan titik lokasi pengambilan sampel gorengan dan minyak goreng.

b. Tahap Pelaksanaan:

1) Pengambilan sampel gorengan dan minyak goreng pada pagi dan sore hari.

2) Identifikasi kandungan plastik pada gorengan secara fisika, dengan cara melihat bentuk gorengan dengan menggunakan mikroskop, warna, kerapuhan, dan uji bakar (Juarnida dan Adlim, 2012) .

3) Analisis kandungan plastik pada minyak goreng secara kimia dilakukan dengan menggunakan instrument GCMS, dengan tahapan preparasi sampel, derivatisasi, injeksi, pemisahan dengan 
GC, deteksi dengan MS, dan scanning (Pavia, Lampman, Kritz, Engel. 2006).

c. Tahap Penyelesaian : menganalisis data hasil identifikasi fisika dan analisis kimia.

Data yang diperoleh dari identifikasi secara fisika dianalisis secara deskriptif berdasarkan kriteria yang telah ditetapkan, yaitu berdasarkan bentuk, warna, kerapuhan, dan uji bakar. Keempat cara identifikasi ini saling melengkapi, karena jika terindikasi di satu cara berkemungkinan tidak terindikasi pada cara yang lain. Jadi keempat cara ini perlu dilakukan untuk memastikan kalau sampel terindikasi mengandung plastik secara fisika.

Hasil analisis secara fisika ini perlu ditindaklanjuti dengan analisis secara kimia. Hal ini dilakukan untuk memastikan apakah gorengan mengandung plastik. Disamping itu dengan analisis kimia bisa diketahui jenis senyawa kimia plastik yang terdapat pada minyak goreng. Analisis secara kimia dilakukan dengan menggunakan instrumen GC-MS. Data yang diperoleh dari GC-MS berupa kromatogram dan spektra massa dari senyawa kandungan plastik dapat dibandingkan dengan acuan dan diidentifikasi dengan referensi komputerisasi. Dengan dilakukan dua analisis ini data/hasil penelitian yang diperoleh menjadi valid dan terpercaya (tidak ada unsur justifikasi tanpa bukti). Jadi kedua analisis ini perlu dilakukan dalam pengujian terhadap sampel makanan.

\section{HASIL DAN PEMBAHASAN}

\section{Identifikasi secara Fisika}

Identifikasi secara fisika dilakukan terhadap bentuk dan warna gorengan, kerapuhan, dan uji bakar. Hasil identifikasi terhadap sampel ditemukan data sebagai berikut ini:

\section{Identifikasi Bentuk dan Warna Gorengan \\ Hasil identifikasi bentuk dan warna gorengan dapat dilihat pada Tabel 2 berikut ini:}

Tabel 2. Hasil Pengamatan terhadap Bentuk dan Warna Sampel Gorengan

\begin{tabular}{|c|c|c|c|}
\hline No & $\begin{array}{l}\text { Beberapa contoh gambar sampel dengan } \\
\text { mikroskop }\end{array}$ & Warna & Ket \\
\hline 1 & 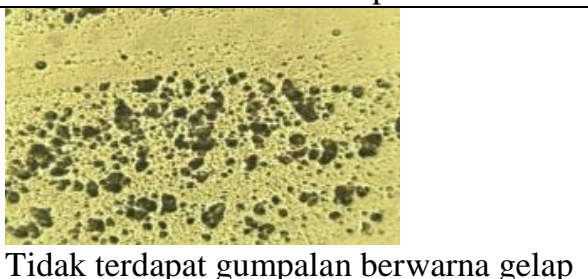 & $\begin{array}{l}\text { Kuning pucat } \\
\text { Terdapat sedikit bercak putih }\end{array}$ & $\begin{array}{l}\text { Tidak } \\
\text { Terindikasi }\end{array}$ \\
\hline 2 & & $\begin{array}{l}\text { Kuning pucat } \\
\text { Terdapat bercak putih }\end{array}$ & Terindikasi \\
\hline 3 & & $\begin{array}{l}\text { Agak pucat } \\
\text { Terdapat sedikit bercak putih }\end{array}$ & Terindikasi \\
\hline
\end{tabular}


4

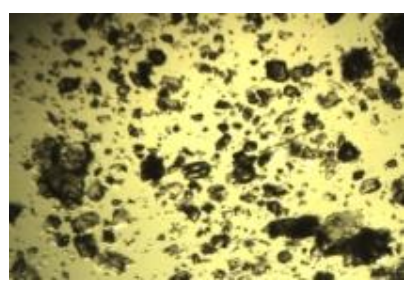

Gumpalan berwarna gelap

5

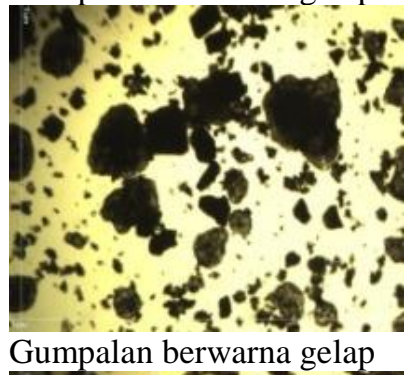

6

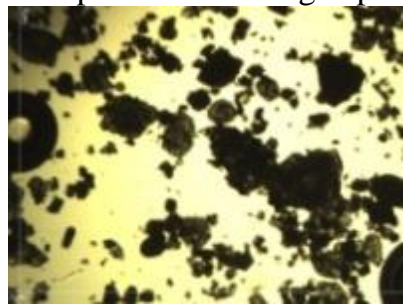

7
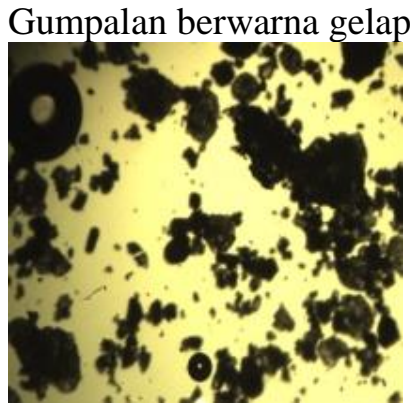

Gumpalan berwarna gelap

8

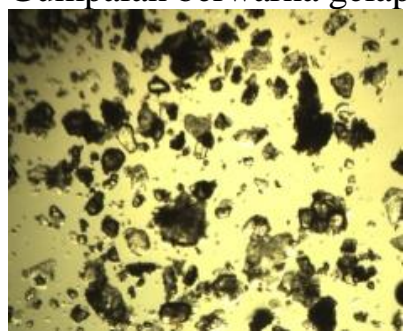

Gumpalan berwarna gelap

9

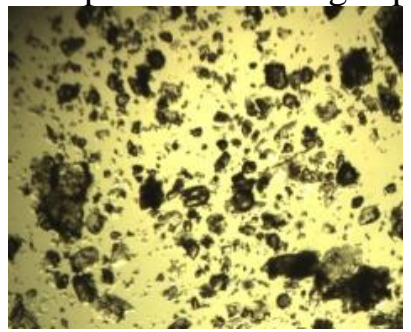

Gumpalan berwarna gelap
Kuning pucat

Terdapat bercak putih

Kuning pucat

Terdapat bercak putih

Kuning pucat

Tidak terdapat bercak putih

Kuning pucat

Terdapat bercak putih

Kuning pucat

Terdapat bercak putih

Kuning pucat

Terdapat bercak putih
Terindikasi

Terindikasi

Terindikasi

Terindi-kasi

Terindikasi

Terindikas

Terindikasi 
Roza, M., Sari, M., Nurhasnah. 2017. Analisis Kandungan Plastik pada Gorengan di Kawasan Perguruan Tinggi Kota Padang. Journal of Sainstek 9(2): 139-150

2. Uji Kerapuhan

Hasil uji kerapuhan terhadap sampel girengan tempe dapat dilihat pada Tabel 3 berikut:

Tabel 3. Hasil Pengamatan terhadap Kerapuhan Sampel Gorengan Tempe

\begin{tabular}{clcc}
\hline No & \multicolumn{1}{c}{ Lokasi } & $\begin{array}{c}\text { Kerapuhan } \\
\text { (selang waktu 12 jam) }\end{array}$ & Ket \\
\hline 1 & UIN, Imam Bonjol & Rapuh & Terindikasi \\
2 & Univ. Bung Hatta, Kuranji & Rapuh & Terindikasi \\
3 & UPI, Lubeg & Rapuh & Terindikasi \\
4 & Dharma Andalas, Lubeg & Rapuh & Terindikasi \\
5 & UNP Ulu Gadut, Luki & Rapuh & Terindikasi \\
6 & Stikes, Nanggolo & Rapuh & Terindikasi \\
7 & STIE-KBP, Padang Barat & Rapuh & Terindikasi \\
8 & FK Unand, Padang Timur & Rapuh & Terindikasi \\
9 & UNP, Padang Utara & Rapuh & Terindikasi \\
10 & STKIP, Padang Utara & Rapuh & Terindikasi \\
11 & Unand, Pauh & Tidak & Tidak Terindikasi \\
12 & ATIP, Koto Tangah & Rapuh & Terindikasi \\
13 & Stikes Perintis, Koto Tangah & Rapuh & Terindikasi \\
14 & STMIK Jaya Nusa, Padang Barat & - & - \\
15 & IAIN, Kuranji (D) & - & \\
16 & IAIN, Kuranji (T) & - & \\
\hline
\end{tabular}

Catatan: Uji kerapuhan hanya dilakukan terhadap gorengan tempe. Jika ada tabel kosong berarti pada titik sampel tersebut tidak menjual tempe goreng.

3. Uji Bakar

Hasil pengamatan terhadap uji bakar gorengan dapat dilihat pada Tabel 4 di bawah ini:

Tabel 4. Hasil Pengamatan terhadap Uji Bakar Sampel Gorengan

\begin{tabular}{|c|c|c|c|c|}
\hline NO & Lokasi & $\begin{array}{c}\text { Terbakar/ } \\
\text { tidak terbakar }\end{array}$ & $\begin{array}{l}\text { Bentuk } \\
\text { Lelehan }\end{array}$ & Ket \\
\hline 1 & IAIN, Imam Bonjol & $\begin{array}{l}\text { Terbakar, } \\
\text { Api Besar }\end{array}$ & $\begin{array}{l}\text { Lelehan } \\
\text { Berwarna Hitam }\end{array}$ & Terindikasi \\
\hline 2 & $\begin{array}{l}\text { Univ. Bung Hatta, } \\
\text { Kuranji }\end{array}$ & $\begin{array}{l}\text { Terbakar, } \\
\text { Api Kecil }\end{array}$ & Lelehan Minyak & Terindikasi \\
\hline 3 & UPI, Lubeg & $\begin{array}{l}\text { Terbakar, } \\
\text { Api Kecil }\end{array}$ & $\begin{array}{l}\text { Tidak ada } \\
\text { Lelehan }\end{array}$ & Tidak Terindikasi \\
\hline 4 & $\begin{array}{l}\text { Dharma Andalas, } \\
\text { Lubeg }\end{array}$ & $\begin{array}{l}\text { Terbakar, } \\
\text { Api Besar }\end{array}$ & Lelehan Minyak & Terindikasi \\
\hline 5 & UNP Ulu Gadut, Luki & $\begin{array}{l}\text { Terbakar, } \\
\text { Api Kecil }\end{array}$ & $\begin{array}{l}\text { Tidak ada } \\
\text { Lelehan }\end{array}$ & Tidak Terindikasi \\
\hline 6 & Stikes, Nanggolo & $\begin{array}{l}\text { Terbakar, } \\
\text { Api Kecil }\end{array}$ & Lelehan Minyak & Terindikasi \\
\hline
\end{tabular}


Roza, M., Sari, M., Nurhasnah. 2017. Analisis Kandungan Plastik pada Gorengan di Kawasan Perguruan Tinggi Kota Padang. Journal of Sainstek 9(2): 139-150

\begin{tabular}{|c|c|c|c|c|}
\hline 7 & $\begin{array}{l}\text { STIE-KBP, Padang } \\
\text { Barat }\end{array}$ & $\begin{array}{l}\text { Terbakar, } \\
\text { Api Besar }\end{array}$ & Lelehan Minyak & Terindikasi \\
\hline 8 & $\begin{array}{l}\text { FK Unand, Padang } \\
\text { Timur }\end{array}$ & $\begin{array}{l}\text { Terbakar, } \\
\text { Api Besar }\end{array}$ & Lelehan Minyak & Terindikasi \\
\hline 9 & UNP, Padang Utara & $\begin{array}{l}\text { Terbakar, } \\
\text { Api Kecil }\end{array}$ & Lelehan Minyak & Terindikasi \\
\hline 10 & STKIP, Padang Utara & $\begin{array}{l}\text { Terbakar, } \\
\text { Api Besar }\end{array}$ & $\begin{array}{l}\text { Lelehan } \\
\text { Berwarna Hitam }\end{array}$ & Terindikasi \\
\hline 11 & Unand, Pauh & - & - & - \\
\hline 12 & ATIP, Koto Tangah & $\begin{array}{l}\text { Terbakar, } \\
\text { Api Besar }\end{array}$ & $\begin{array}{l}\text { Lelehan } \\
\text { Berwarna Hitam }\end{array}$ & Terindikasi \\
\hline 13 & $\begin{array}{l}\text { Stikes Perintis, Koto } \\
\text { Tangah }\end{array}$ & $\begin{array}{l}\text { Terbakar, } \\
\text { Api Besar }\end{array}$ & $\begin{array}{l}\text { Lelehan } \\
\text { Berwarna Hitam }\end{array}$ & Terindikasi \\
\hline 14 & $\begin{array}{l}\text { STMIK Jaya Nusa, } \\
\text { Padang Barat }\end{array}$ & - & - & - \\
\hline 15 & IAIN, Kuranji (D) & - & - & - \\
\hline 16 & IAIN, Kuranji (T) & - & - & - \\
\hline
\end{tabular}

Catatan: Uji bakar hanya dilakukan terhadap tempe goreng. Jika ada tabel kosong berarti pada titik sampel tersebut tidak menjual tempe goreng.

\section{Analisis secara Kimia}

Analisis secara kimia terhadap sampel minyak goreng dapat dilihat pada Tabel 5 berikut:

Tabel 5. Analisis Kimia dengan GC-MS

\begin{tabular}{|c|c|c|c|}
\hline NO & Lokasi & $\begin{array}{l}\text { Retention } \\
\text { Time (RT) }\end{array}$ & Keterangan \\
\hline 1 & IAIN, Imam Bonjol & - & Tidak mengandung plastik \\
\hline 2 & Univ. Bung Hatta, Kuranji & - & Tidak mengandung plastik \\
\hline 3 & UPI, Lubeg & - & Tidak mengandung plastik \\
\hline 4 & Dharma Andalas, Lubeg & $\begin{array}{l}5,011 \\
8,742\end{array}$ & Mengandung senyawa plastik \\
\hline 5 & UNP Ulu Gadut, Luki & - & Tidak mengandung plastik \\
\hline 6 & Stikes, Nanggolo & 17,886 & Mengandung senyawa plastik \\
\hline 7 & STIE-KBP, Padang Barat & 15,707 & Mengandung senyawa plastik \\
\hline 8 & FK Unand, Padang Timur & $\begin{array}{l}15,700 \\
17,892\end{array}$ & Mengandung senyawa plastik \\
\hline 9 & UNP, Padang Utara & $\begin{array}{c}8,711 \\
17,886\end{array}$ & Mengandung senyawa plastik \\
\hline 10 & STKIP, Padang Utara & 10,997 & Mengandung senyawa plastik \\
\hline 11 & Unand, Pauh & - & Tidak mengandung plastik \\
\hline 12 & ATIP, Koto Tangah & 10,468 & Mengandung senyawa plastik \\
\hline 13 & Stikes Perintis, Koto Tangah & $\begin{array}{c}8,350 \\
15,700\end{array}$ & Mengandung senyawa plastik \\
\hline 14 & STMIK Jaya Nusa, Padang Barat & 15,701 & Mengandung senyawa plastik \\
\hline 15 & IAIN, Kuranji (D) & 15,710 & Mengandung senyawa plastik \\
\hline 16 & IAIN, Kuranji (T) & $\begin{array}{l}15,715 \\
16,022\end{array}$ & Mengandung senyawa plastik \\
\hline
\end{tabular}




\section{Contoh hasil Uji GC MS}

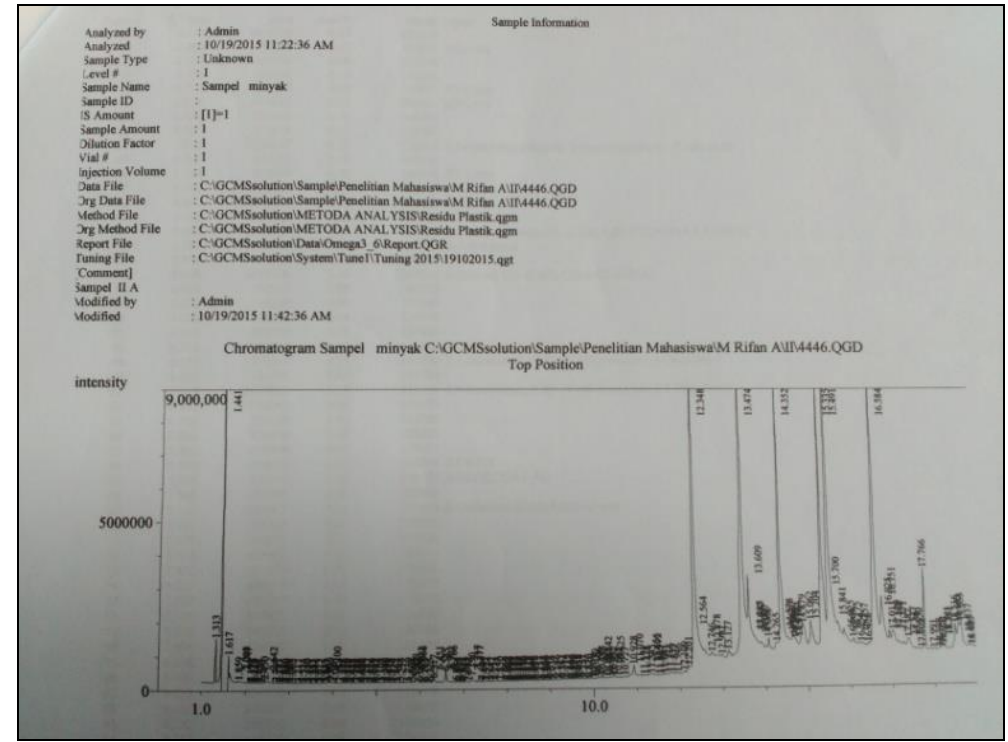

Gambar 1. Sampel hasil kromatogram minyak goreng yang tidak mengandung plastik

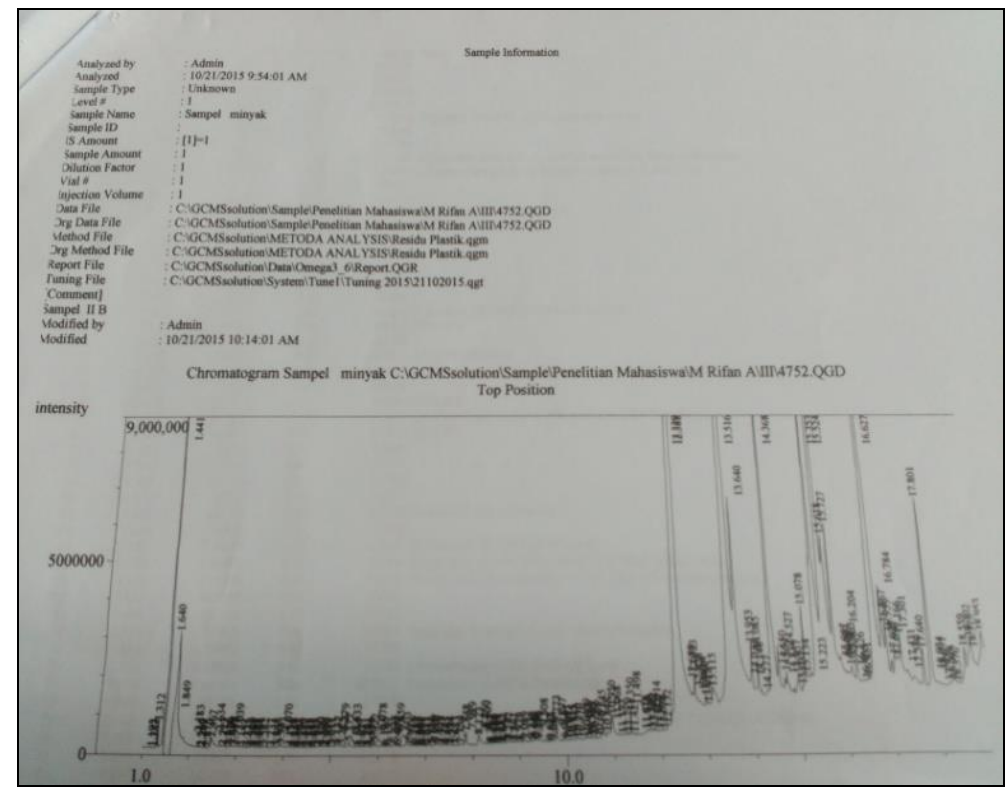

Gambar 2. Sampel hasil kromatogram minyak goreng yang mengandung plastik

\section{Pembahasan}

\section{Identifikasi secara Fisika}

Hasil identifikasi dengan menggunakan mikroskop (data pada Tabel 2) terlihat bahwa bentuk sampel gorengan ada yang terdapat gumpalan berwarna gelap dan ada yang tidak/sedikit terlihat gumpalan gelapnya. Adanya gumpalan berwarna gelap mengindikasikan bahwa sampel gorengan tersebut mengandung plastik, sedangkan yang sedikit/tidak terdapat gumpalan berwarna gelap mengindikasikan bahwa tidak terdapat plastik 
pada sampel gorengan tersebut. Hal ini sesuai dengan hasil penelitian yang dilakukan oleh Juarnida dan Adlim (2012). Dari 16 sampel yang dianalisis terdapat 8 sampel yang terindikasi mengandung plastik, 4 sampel tidak terindikasi mengandung plastik, dan 4 sampel lagi tidak dilakukan uji mikroskop karena tidak ada gorengan tempe pada titik lolasi pengambilan sampel.

Identifikasi terhadap warna sampel gorengan menunjukkan hasil bahwa ada 9 sampel yang berwarna kuning pucat dan 2 sampel berwarna agak kuning pucat. Kemudian jika dilihat dari ada atau tidaknya bercak putih, diperoleh 12 sampel yang mengandung bercak putih, dan 4 sampel tidak mengandung/sedikit bintik putih. Menurut Juarnida dan Adlim (2012) dan Husnah (2013) gorengan yang mengandung plastik biasanya terdapat bercak putih. Dari data yang diperoleh, kesimpulan sementara adalah bahwa sampel yang terindikasi mengandung plastik sebanyak 11 sampel, dan yang tidak terindikasi sebanyak 5 sampel.

Uji kerapuhan sampel (data pada Tabel 3) dilakukan terhadap gorengan tempe. Dari 16 titik lokasi pengambilan sampel hanya 13 titik yang menjual tempe. Dan dari 13 sampel tersebut, 12 sampel rapuh selama 12 jam, dan 1 sampel tidak. Menurut Husnah (2013) gorengan yang kerenyahannya bertahan lama mengindikasikan bahwa gorengan tersebut mengandung plastik.

Hasil uji bakar terhadap sampel gorengan (data pada Tabel 4), dilakukan terhadap 12 sampel gorengan tempe. Dari 12 sampel tersebut, semua sampel terbakar dan menyala dimana 7 sampel menyala dengan api besar, sedangkan 5 sampel lainnya menyala dengan api kecil. Dilihat dari bentuk lelehannya, 4 sampel lelehannya berwarna hitam, dan 6 sampel lelehannya berupa minyak, dan 2 sampel tidak ada lelehan. Menurut Shohibi (2011) dan Juarnida dan Adlim (2012), gorengan yang mengandung plastik pada saat dibakar akan meneteskan cairan yang berasal dari lelehan plastik tersebut, karena plastik yang digunakan bersifat termoplastik. Kesimpulan untuk uji bakar ini bahwa 10 sampel terindikasi mengandung senyawa plastik

\section{Analisis secara Kimia}

Dari 16 sampel yang diidentifikasi secara fisika, diperoleh data yang saling melengkapi untuk uji fisika, dimana terdapat 15 sampel yang terindikasi mengandung plastik. Sampel yang terindikasi mengandung plastik secara uji fisika tersebut kemudian dianalisis dengan GCMS. Hasil GC-MS menunjukkan bahwa 11 sampel $(68,75 \%)$ terbukti secara kimia mengandung senyawa plastik (data pada Tabel 5). Adapun jenis senyawa plastik yang terdeteksi secara kimia adalah:

a. Butylphthalate

b. 4,5dihydro 3-n-butil phthalida

c. 1,2-benzenedicarboxylicacid, diethyl eter (ethyl phthalate)

d. 1,2- benzenedicarboxylicacid, bis (2ethylhexy ester (bis (2ethylhexy) phthalate

e. 13-oxbicyclo (10.1.0)tridecane (epoxycylododecane)

f. 1,2-benzenedicarboxylicacid, diisoctyl eter (isooctyl phthalate)

g. 3,9-cis-6,7-epoxy-nonadecane

h. 1,2-benzenedicarboxylicacid, dibutyl ester (butyl phthalate)

i. 13-oxbicyclo

(10.1.0)tridecane (epoxycylododecane)

j. 2-propeonic acid, 2 methyl, ethil ester (ethyl methacrylate)

k. Decane,1(ethenyloxy)-decyl vinyl ether

Dari kandungan senyawa tersebut, pada umumnya jenis bahan berbahaya yang terdapat dalam minyak goreng tersebut adalah bis(2ethylhexyl) phthalate (BEHP). Senyawa ini disebut juga di(-2ethylhexyl) phthalate (DEHP), merupakan senyawa pthalate. Pthalate merupakan bahan yang memberikan sifat lembut dan fleksibel (plastilizer) yang biasanya digunakan pada plastik jenis PVC (Polyvinyl chloride). PVC biasanya digunakan sebagai pot yoghurt, kantong belanja (kresek), kantong roti dan makanan segar, dan botol yang dapat ditekan.

Phthalates yang dibakar/dipanaskan dapat melepaskan dioksin dan merkuri sehingga 
dapat mempengaruhi kesehatan masyarakat sekitarnya dalam jangka waktu yang lama, termasuk kanker, cacat lahir, perubahan hormon, penurunan jumlah sperma, infertilitas, endometriosis dan gangguan sistem imun (Direktorat Pengawasan Produk dan Bahan Berbahaya BPOM, 2008).

Menurut Kenneth K. Wu, Presiden Institute Riset Kesehatan Nasional, Taiwan, makanan yang tercemar oleh pengemulsi plasticizer DEHP tersebut dapat mengakibatkan penyakit kanker dan leukemia, serta penyakit endocrine disruptors yang dapat memicu ketidaknormalan sistem reproduksi khususnya laki-laki, dengan resiko delapan kali lebih besar bagi anak-anak di banding konsumen dewasa. Karena alasan tersebut konsumen muda usia akan menjadi korban yang paling beresiko terkena efek berbahaya bila senyawa DEHP terkonsumsi oleh mereka (Asosiasi Laboratorium Pangan Indonesia, 2011).

\section{KESIMPULAN}

Identifikasi secara Fisika

Hasil analisis secara fisika melalui uji bakar, uji kerapuhan, bentuk, dan uji warna maka sebagian besar gorengan yang dijual di kota Padang terindikasi mengandung plastik, yaitu :

1. Uji bakar; dari 16 titik sampel, 5 titik terindikasi mengandung plastik

2. Uji warna; dari 16 titik sampel, 7 titik terindikasi mengandung plastik

3. Uji kerapuhan; dari 16 titik sampel, 11 titik terindikasi mengandung plastik

4. Uji bentuk (mikroskop); dari 16 titik sampel 7 titik terindikasi mengandung plastik

Analisis secara Kimia

Jenis plastik yang ditemukan dalam minyak goreng setelah dianalisis dengan GC MS yaitu:

1. Butylphthalate

2. 4,5dihydro 3-n-butil phthalida

3. 1,2-benzenedicarboxylicacid, diethyl eter (ethyl phthalate)

4. 1,2- benzenedicarboxylicacid, bis (2ethylhexy ester (bis (2ethylhexy) phthalate
5. 13-oxbicyclo (epoxycylododecane)

(10.1.0)tridecane

6. 1,2-benzenedicarboxylicacid, diisoctyl eter (isooctyl phthalate)

7. 3,9-cis-6,7-epoxy-nonadecane

8. 1,2-benzenedicarboxylicacid, dibutyl ester (butyl phthalate)

9. 13-oxbicyclo

(10.1.0)tridecane (epoxycylododecane)

10.2-propeonic acid, 2 methyl, ethil ester (ethyl methacrylate)

11.Decane,1(ethenyloxy)-decyl vinyl ether

\section{Rekomendasi}

Berdasarkan temuan penelitian, dapat diajukan beberapa rekomendasi kepada:

1. Pimpinan kampus IAIN Imam Bonjol Padang

Hasil penelian ini diharapkan menjadi bahan pertimbangan untuk Pengabdian kepada Masyarakat. Salah satunya berupa kegiatan pembinaan kepada para pedagang terutama pedagang gorengan. Hasil pembinaan dapat berupa model pembinaan terhadap penjual gorengan yang sehat.

2. Badan Pengawasan Obat dan Makanan (BPOM)

Pihak BPOM dapt menindaklanjuti hasil penelitian ini dengan melakukan pengujian terhadap sampel yang lebih bervariatif dan lebih luas, misalnya sampel di sekolah/madrasah dan pasar-pasar tradisional. Kemudian melakukan sosialisasi tentang bahaya plastik dan zat aditif berbahaya lainnya pada makanan terhadap kesehatan.

3. Pemerintahan Kota Padang

Kepada Pemko Padang diharapkan dapat melakukan pembinaan terhadap penjual gorengan supaya menjual gorengan yang sehat.

\section{DAFTAR KEPUSTAKAAN}

Asosiasi Laboratorium Pangan Indonesia. 2011. DEHP, Plasticizer yang Sering Terdapat dalam Bahan Emulsifier. http://alpindonesia.org/berita/index1.ph p? Diakses 2 Oktober 2015. 
Direktorat Pengawasan Produk dan Bahan Berbahaya BPOM. 2008. Plastik sebagai Kemasan Pangan.

D’Buletin. 2008. Bahaya Dibalik Kemasan Makanan Plastik. http://elit38.wordpress.com. Diakses 6 Desember 2014.

Fahimah. 2012. Hidup Kita Dekat dengan Senyawa Kimia Berbahaya. http:// humaniora.kompasiana.com. Diakses 6 Desember 2014.

Hartanto D. 2012. Masih Ditemukan Gorengan Bercampur Plastik di Jaksel. http://ikebayoran.com. Diakses 6 Desember 2014.

Husnah, Nurul A. 2013. Penambahan Bahan Plastik dalam Proses Penggorengan Berdampak Bagi Kesehatan. Malang: Kimia FMIPA UNM.

Juarnida dan Adlim. 2012. Mengidentifikasi Kandungan Plastik dalam Makanan Gorengan pada Sampel Simulasi. Banda Aceh: Kimia FKIP Universitas Syiah Kuala.

Laksmi SB. 2001. Potensi dan Prospek Bioteknologi dalam Rangka Penyediaan Pangan Menyehatkan.
Bogor: Fakultas Teknologi Pertanian, Jurusan Teknologi Pangan dan Gizi Institut Pertanian Bogor.

Media Islam. 2012. Makanan yang Halal dan Baik (Halalan Thoyiban). Tersedia di http://mediaislam. or.id/2012/05/14/makananyanghalaldan baikhalalanthoyyiban/. Di akses 6 Maret 2015.

Nugroho SH. 2004. Ancaman Polimer Sintetik bagi Kesehatan Manusia (Bagian II) http://www.chem-is-try.org. Diakses 23 Januari 2015.

Padang Ekspres. 2015. Awas! Beredar Makanan Berbahaya. 21 Mei 2015 hal.1-7.

Pavia DL, Lampman GM, Kritz GS, Randall G, Engel RG. 2006. Introduction to Organic Laboratory Techniques (4th $E d$.). New York: Thomson Brooks/Cole.

Shohibi. 2011. Minyak Gorengan Campur Plastik (Hasil Investigasi). http://sohibi.blogspot.com. Diakses 6 Desember 2014.

Arikunto S. 2006. Prosedur Penelitian. Jakarta: Rineka Cipta. 